\title{
Ärztekammersitzung
}

\section{Bereits feststehende Traktanden}

- Begrüssung, Mitteilungen

- Ambulanter Tarif

- Grundsanierung Liegenschaft Elfenstrasse: Nachtragskredit

- Monistische Finanzierung

- Jahresbericht 2018

- Bericht 2018 Umsetzung Budgetstabilisierungsmassnahmen

- Jahresrechnung 2018

- Dechargen-Erteilung

- Wahlen und Bestätigungswahlen

- Änderungen in Statuten, Geschäftsordnung und Standesordnung

- Finanzierung von Anträgen auf finanzielle Unterstützung von politischen Vorstössen

- Informationen aus Zentralvorstand, Generalsekretariat, SIWF und Abteilungen

- Varia

Neue Traktanden sind bis am 3. April 2019 an das Zentrale Sekretariat (direction[at]fmh.ch) einzureichen. 